\title{
Expression of lysophosphatidic acid acyltransferase beta (LPAAT- $\beta$ ) in ovarian carcinoma: correlation with tumour grading and prognosis
}

\author{
S Niesporek ${ }^{1,5}$, C Denkert ${ }^{*, 1,5}$, W Weichert', M Köbel' ${ }^{2}$, A Noske', J Sehouli ${ }^{3}$, JW Singer ${ }^{4}$, M Dietel' and \\ S Hauptmann ${ }^{2}$
}

IInstitute of Pathology, Charité University Hospital, Campus Mitte, Schumannstr. 20/21, 10117 Berlin, Germany; ${ }^{2}$ Institute of Pathology, Martin-LutherUniversity Halle-Wittenberg, Magdeburger Str. 14,061 12 Halle (Saale), Germany; ${ }^{3}$ Department of Gynecology and Obstetrics, Charité University Hospital, Campus Virchow Klinikum, Augustenburger Platz I, 13353 Berlin, Germany; ${ }^{4}$ Cell Therapeutics Inc., 501 Elliott Avenue West, Suite 400, Seattle, WA 98119 , USA

Lysophosphatidic acid acyltransferase beta (LPAAT- $\beta$ ) is an enzyme involved in lipid biosynthesis whose role in tumour progression has been of emerging interest in the last few years. We investigated the expression of LPAAT- $\beta$ by reverse transcriptase-polymerase chain reaction and immunohistochemistry in 10 ovarian cell lines as well as in a cohort of 106 ovarian tumours and normal ovaries. Lysophosphatidic acid acyltransferase beta mRNA was found in all cell lines and ovarian tumours examined. Expression of LPAAT- $\beta$ protein was significantly increased in ovarian carcinomas compared to benign ovarian tissue $\left(\chi^{2}\right.$ test $P$-value $=0.00 \mathrm{I}$, Kruskal - Wallis test $P$-value $<0.000 \mathrm{I})$. Furthermore, LPAAT- $\beta$ expression was positively associated with higher tumour grade $(P=0.044)$, higher mitotic index $(P<0.000 \mathrm{I})$ and tumour stage $(P=0.032)$. Expression of LPAAT- $\beta$ was significantly linked to reduced overall survival time $(P=0.024)$ as well as to shorter progression-free survival time $(P=0.012)$ in patients younger than 60 years. Our study shows that LPAAT $\beta$ is upregulated in ovarian cancer and is more prevalent in poorly differentiated tumours. In addition, LPAAT- $\beta$ expression is a predictor of a worse prognosis in patients younger than 60 years. Further studies are needed to investigate if LPAAT- $\beta$ may serve as a therapeutic target for certain subgroups of patients.

British Journal of Cancer (2005) 92, 1729- 1736. doi: 10.1038/sj.bjc.6602528 www.bjcancer.com

Published online 19 April 2005

(c) 2005 Cancer Research UK

Keywords: LPAAT- $\beta$; ovarian cancer; phosphatidic acid

Ovarian carcinoma, although constituting only about $5 \%$ of all malignancies of the female genital tract, is still the gynaecological cancer with the highest mortality (Jemal et al, 2004). This is mainly due to the usually late detection of this neoplasm. In contrast to breast or cervical cancer, no sufficient screening methods exist for ovarian carcinoma and in contrast to endometrial carcinoma, it is mostly asymptomatic in early stages. Thus, most patients are diagnosed with stage III or IV carcinomas that have already spread to adjacent anatomic structures in the peritoneal cavity. In these stages, chemotherapy in addition to radical surgery is the therapeutic option (Almadrones, 2003; Pfisterer et al, 2003). Therefore, research on the pathogenetic basis of this neoplasm might be of great value for the development of new molecular therapies, which specifically target molecules that enhance tumorigenic properties.

Lysophosphatidic acid acyltransferase beta (LPAAT- $\beta$ ) is an enzyme that has been of growing interest in tumour research in the

\footnotetext{
*Correspondence: Dr C Denkert;

E-mail: carsten.denkert@charite.de

${ }^{5}$ These authors contributed equally to the publication

Received 4 October 2004; revised 8 February 2005; accepted 28 February 2005; published online 19 April 2005
}

last few years. It converts intracellular lysophosphatidic acid (LPA) to phosphatidic acid (PA). Apart from its counterpart LPA that is already well known as a stimulator of cell proliferation, migration and survival and whose role in tumorigenesis, especially in ovarian cancer, has been extensively examined (Mills and Moolenaar, 2003), PA has emerged as another bioactive phospholipid important in cancer biology because of its implication in a variety of signal transduction pathways (English, 1996). The LPAAT family comprises several members with the most important being LPAAT- $\alpha$ and LPAAT- $\beta$ (Eberhardt et al, 1997; West et al, 1997; Aguado and Campbell, 1998; Li et al, 2003). While LPAAT- $\alpha$ is expressed in all human tissues and is therefore thought to have a housekeeping function, LPAAT- $\beta$ is differentially expressed, with the highest levels in liver and heart but also in steroid hormonedependent tissues such as prostate, endometrium and ovary (West et al, 1997; Leung, 2001).

In this study, we investigated the expression of LPAAT- $\beta$ by reverse transcriptase-polymerase chain reaction (RT-PCR) and immunohistochemistry in 10 ovarian cell lines as well as in a cohort of 106 ovarian tumours and normal ovaries. The aim of our study was to evaluate the prognostic role of LPAAT- $\beta$ expression and its association with clinicopathological factors. 


\section{PATIENTS AND METHODS}

\section{Cell lines}

The human ovarian carcinoma cell lines OVCAR-3, SKOV-3, MDAH-2774 and CAOV-3 have been isolated from ovarian adenocarcinomas and were obtained from the American Type Culture Collection (ATCC, Rockville, MD, USA). OAW-42 and A27/80 have been established from adenocarcinomas of the ovary, and were from the European Collection of Cell Cultures (ECACC, Salisbury, UK). EFO-27 has been established from an ovarian adenocarcinoma and was obtained from the German Collection of Microorganisms and Cell Cultures (DSM, Braunschweig, Germany). The cell line ES-2 has been isolated from a poorly differentiated ovarian clear-cell carcinoma and was from ATCC. PA-1 has been established from an ovarian teratocarcinoma and was from ATCC. HOSE, a normal ovarian surface epithelium cell line, which has been immortalised by HPV, was a kind gift from Dr SW Tsao (Universtity of Hong-Kong, Department of Anatomy) (Tsao et al, 1995). Cell lines were cultured in Dulbecco's modified Eagle's medium supplemented with $10 \%$ fetal bovine serum.

\section{Polymerase chain reaction}

Tissue from ovarian carcinomas was dissected by a senior pathologist in the operating room from surgical specimens sent for frozen section analysis and was immediately frozen in liquid nitrogen and stored at $-80^{\circ} \mathrm{C}$ until analysis. Tissue samples were homogenised and total RNA was extracted with the RNeasy Kit. Residual DNA was digested with DNase. For polymerase chain reaction (PCR) of RNA, cDNA was made by reverse transcription. Polymerase chain reaction was performed following the subsequent protocol: cycling conditions were 35 cycles of denaturation, annealing and extension $\left(94^{\circ} \mathrm{C}\right.$ for $60 \mathrm{~s}, 55^{\circ} \mathrm{C}$ for $60 \mathrm{~s}, 72^{\circ} \mathrm{C}$ for $\left.60 \mathrm{~s}\right)$. Primers used were human LPAAT- $\beta$ sense $5^{\prime}$-CGCTCTAG CACTGCCATGAC- $3^{\prime}$ and LPAAT- $\beta$ antisense $5^{\prime}$-CCAGCACCTG CAATGTGACT-3' (generating a 253-bp band) and human GAPDH sense $5^{\prime}$-CCATGGCACCGTCAAGGCTG- $3^{\prime}$ and GAPDH antisense $5^{\prime}$-GCCATGTGGGCCATGAGGTC-3' (generating an 828-bp band).

\section{Study population}

Immunohistochemical analysis was performed retrospectively on tissue samples collected from 106 patients who underwent surgery for diagnostic or therapeutic purpose at the Charite University Hospital Berlin, Germany and the RWTH Aachen, Germany between 1989 and 2000. This study has been approved by the ethics committee of the Charite Hospital. Data on histology, tumour size, nodal status and FIGO stage were extracted from the pathological report at primary diagnosis. The carcinomas were graded according to the Silverberg grading system, which takes account of nuclear polymorphism, mitotic figure count and architectural features (Shimizu et al, 1998). For statistical evaluation and survival analysis, only the cases of invasive ovarian carcinoma were included.

Follow-up data on overall survival were available for all patients. Overall survival was defined as the time between diagnosis and death. Data on progression-free survival were available for 51 of 76 (67\%) patients. Progression-free survival was defined as the time between diagnosis and the first clinical or pathological evidence of local or distant disease recurrence.

\section{Immunohistochemistry}

Immunohistochemistry was performed using standard procedures. For detection of LPAAT- $\beta$ on tissue samples, we used a mouse monoclonal antibody against human LPAAT- $\beta$, which was from JW Singer, Cell Therapeutics, Seattle, USA (Bonham et al, 2003).
For antigen retrieval, slides were boiled for $5 \mathrm{~min}$ in $0.01 \mathrm{M}$ sodium citrate buffer, $\mathrm{pH}$ 6.0, in a pressure cooker. Slides were incubated with the primary antibody diluted 1:200 in antibody diluent solution (Zymed, San Francisco, CA, USA) for $20 \mathrm{~min}$ at room temperature and then at $4{ }^{\circ} \mathrm{C}$ overnight. After washing slides in TBS, a streptavidin-biotin system was applied according to a standard protocol with standard antibody dilutions as provided by the manufacturer (BioGenex, San Ramon, CA, USA). For colour development, a fast red system (Sigma, Deisenhofen, Germany) was used. After colour development was stopped, slides were coverslipped using Aquatex (Merck, Gernsheim, Germany).

\section{Evaluation of immunohistochemical staining}

Immunohistochemical staining was evaluated by two pathologists (CD and $\mathrm{SN}$ ) who were blinded towards patient's characteristics and outcome. For semiquantitative analysis of staining, an immunoreactivity scoring system (IRS) was applied. For this purpose, the mean number of cells stained $(0=$ no cells stained, $1=$ less than $10 \%$ of cells stained, $2=11-50 \%$ of cells stained, $3=51-80 \%$ of cells stained, $4=$ more than $80 \%$ of cells stained) as well as staining intensity $(0=$ negative, $1=$ weak, $2=$ moderate, $3=$ strong) was evaluated. Subsequently, the respective score for each case was calculated by multiplication of these two parameters. Those cases, in which disagreement in IRS score evaluation between both observers was evident, were discussed using a multiheaded microscope, until agreement was achieved. For statistical analysis, cases with an IRS of 0-6 were grouped in one group ('LPAAT- $\beta$-negative') and were compared to cases with an IRS of 7-12 ('LPAAT- $\beta$-positive').

\section{Statistical analysis}

Association between clinicopathological parameters and expression of LPAAT- $\beta$ was assessed using either $\chi^{2}$ test, $\chi^{2}$ test for trends, Fisher's exact test, Kruskal-Wallis test or Mann-Whitney test. Survival curves were established by the Kaplan-Meier method and compared by applying a log-rank test. Generally, $P$-values smaller than 0.05 were considered significant. For all statistical procedures, SPSS v10.0 software was used.

\section{RESULTS}

\section{Expression of LPAAT- $\beta$ mRNA in ovarian carcinoma cell lines}

To investigate expression of LPAAT- $\beta$ mRNA in ovarian cancer, we studied eight ovarian adenocarcinoma cell lines as well as one ovarian teratocarcinoma cell line by RT-PCR. In addition, an immortalised normal ovarian surface epithelium cell line (HOSE) was examined. All cell lines expressed LPAAT- $\beta$ mRNA constitutively. Lysophosphatidic acid acyltransferase beta mRNA was increased in most cancer cell lines compared to the normal ovarian surface epithelium cell line HOSE. Expression level of GAPDH, the positive control, was similar in all cell lines (Figure 1A).

\section{Expression of LPAAT- $\beta$ mRNA in ovarian carcinomas}

We investigated five ovarian carcinomas, one borderline tumour, one benign ovarian teratoma and one normal ovary (Figure 1B). A moderate expression of LPAAT- $\beta$ mRNA was detected in five cases. Three cases, one G2 and one G3 serous carcinoma, and one clear-cell carcinoma, showed only weak expression of LPAAT- $\beta$ mRNA. Expression level of GAPDH, the positive control, was comparable in all cases. 
A

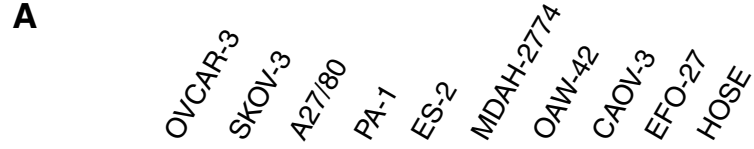

LPAAT- $\beta$

(253 bp)

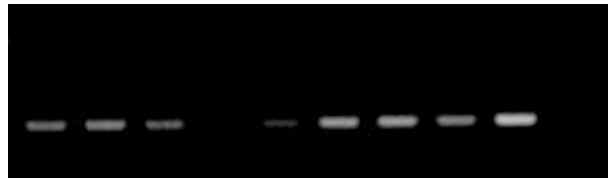

GAPDH

(828 bp)

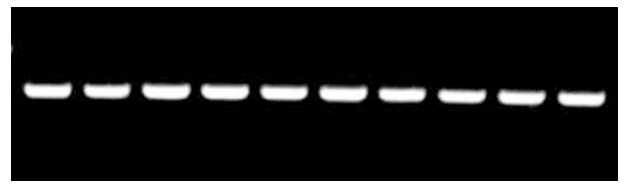

B

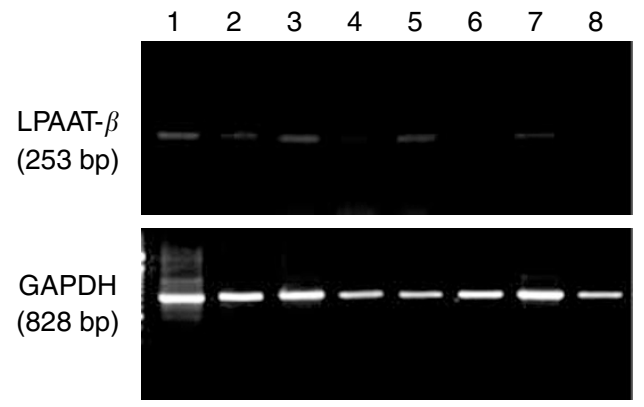

Figure I Expression of LPAAT- $\beta$ mRNA in eight ovarian carcinoma cell lines, one ovarian teratocarcinoma cell line and one normal ovarian surface epithelium cell line $(\mathbf{A})$. Expression of LPAAT- $\beta$ mRNA in eight cases of ovarian tissue. Histological diagnoses: ( I) endometrioid carcinoma, G2; (2) serous carcinoma, G3; (3) benign teratoma; (4) serous carcinoma, G2; (5) normal ovary; (6) serous carcinoma, G3; (7) serous borderline tumour; (8) clear-cell carcinoma (B). Expression of LPAAT- $\beta$ and GAPDH was determined by RT-PCR. bp = base pairs.
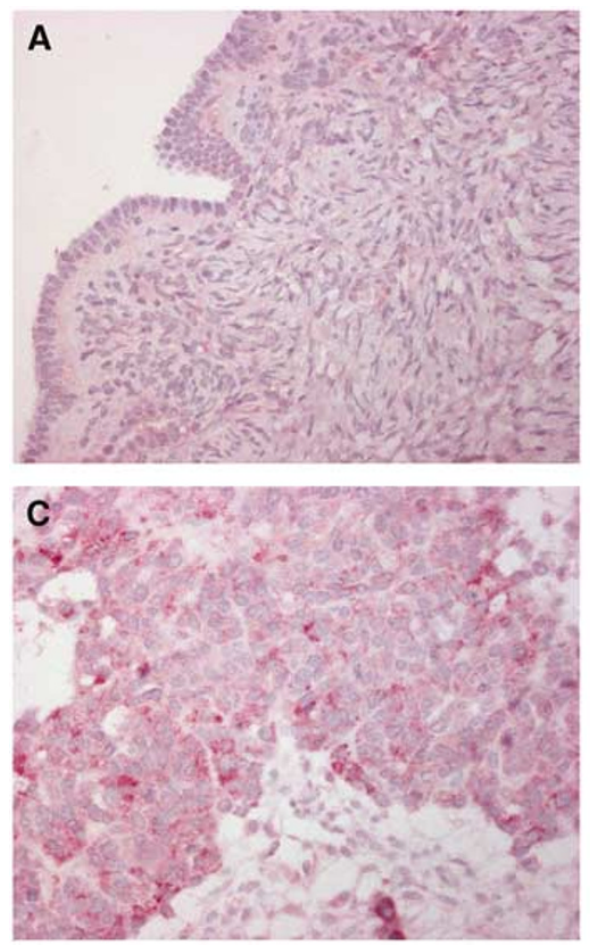

Clinical and pathological characteristics of patients with ovarian lesions

As our results have shown that LPAAT- $\beta$ mRNA was present in most samples from ovarian carcinomas, we further studied the LPAAT- $\beta$ protein expression by immunohistochemistry in ovarian tissue of 106 patients. The median age at surgery was 57 years (range 28-85 years). In all, 76 (71\%) patients had an invasive ovarian carcinoma, $16(15 \%)$ had a borderline tumour, seven (7\%) had a benign cystadenoma and seven (7\%) had normal ovaries. Of the invasive carcinomas, $39(51 \%)$ were of the serous type, seven (9\%) mucinous, $11(15 \%)$ endometrioid, four $(5 \%)$ clear cell, three (4\%) transitional cell and $12(16 \%)$ undifferentiated carcinomas. Carcinomas were well differentiated (G1) in 18 (23\%) cases, moderately differentiated (G2) in $31(41 \%)$ cases and poorly differentiated (G3) in $27(35 \%)$ cases. Tumour stage was pT1 in 15 $(20 \%)$ cases, pT2 in $13(17 \%)$ cases and pT3 in $48(63 \%)$ cases. Data on the nodal status were available for $46(60 \%)$ patients of whom $25(54 \%)$ patients had no lymph node metastasis and 21 $(46 \%)$ have been classified as pN1. Four (5\%) patients in our study group had known distant metastases (pM1) at the time of diagnosis. In all, $16(21 \%)$ patients were staged as FIGO I, 11 (15\%) as FIGO II and 45 (59\%) as FIGO III. The four (5\%) patients with distant metastases were classified as FIGO stage IV.

Overall survival of ovarian carcinoma patients ranged from 0.3 to 122 months with a median survival of 35 months. A total of 35 (46\%) patients died during follow-up. A total of 26 of $51(51 \%)$ patients had clinical or pathological evidence of disease recurrence during follow-up. In five (19\%) of these 26 patients, disease recurrence was clinically manifest as distant metastasis, while 21 patients $(81 \%)$ had a local recurrence.

\section{Expression of LPAAT- $\beta$ in ovarian tissue}

Immunoreactivity for LPAAT- $\beta$ was detectable in a subset of ovarian carcinomas as well as in benign ovarian tissue.
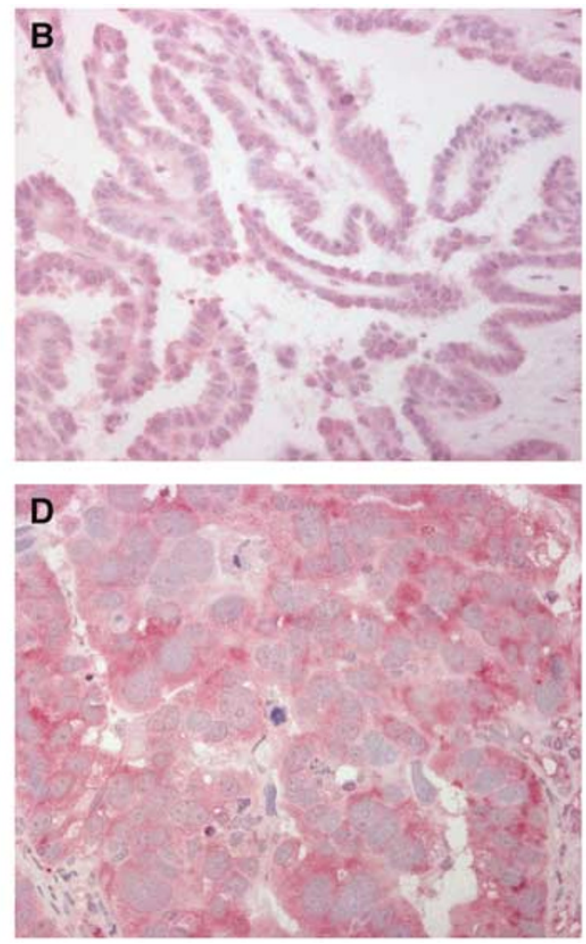

Figure 2 Immunohistochemical detection of LPAAT- $\beta$ expression in a normal ovary as well as in ovarian carcinomas. Normal ovarian surface epithelium with weak expression of LPAAT- $\beta$ (A). Serous ovarian carcinoma (GI) with moderate expression of LPAAT- $\beta$ (B). Transitional cell ovarian carcinoma (G3) with strong expression of LPAAT- $\beta$ (C). Serous ovarian carcinoma (G3) with strong expression of LPAAT- $\beta$ (D). In all samples shown, a weak stromal expression of LPAAT- $\beta$ is evident. 
Lysophosphatidic acid acyltransferase beta was expressed in a cytoplasmatic staining pattern in tumour cells (Figure 2), which is consistent with previous demonstration of LPAAT- $\beta$ localisation to the endoplasmic reticulum (Leung, 2001). We found a positive staining in $50(66 \%)$ ovarian carcinomas, whereas three $(19 \%)$ borderline tumours, two (29\%) benign cystadenomas and two (29\%)

Table I Expression of LPAAT- $\beta$ in normal ovaries and different types of ovarian tumours

\begin{tabular}{lcccc}
\hline Tissue type & All cases & $\begin{array}{l}\text { LPAAT- } \\
\boldsymbol{\beta} \text {-negative }\end{array}$ & $\begin{array}{l}\text { LPAAT- } \\
\boldsymbol{\beta} \text {-positive }\end{array}$ & $\boldsymbol{P}$-value \\
\hline Invasive carcinoma & $76(100 \%)$ & $26(34 \%)$ & $50(66 \%)$ & \\
Borderline tumour & $16(100 \%)$ & $13(81 \%)$ & $3(19 \%)$ & \\
Cystadenoma & $7(100 \%)$ & $5(71 \%)$ & $2(29 \%)$ & $0.001^{\text {a }}$ \\
Normal ovary & $7(100 \%)$ & $5(71 \%)$ & $2(29 \%)$ & \\
\hline
\end{tabular}

a Pearson's $\chi^{2}$, two-sided.
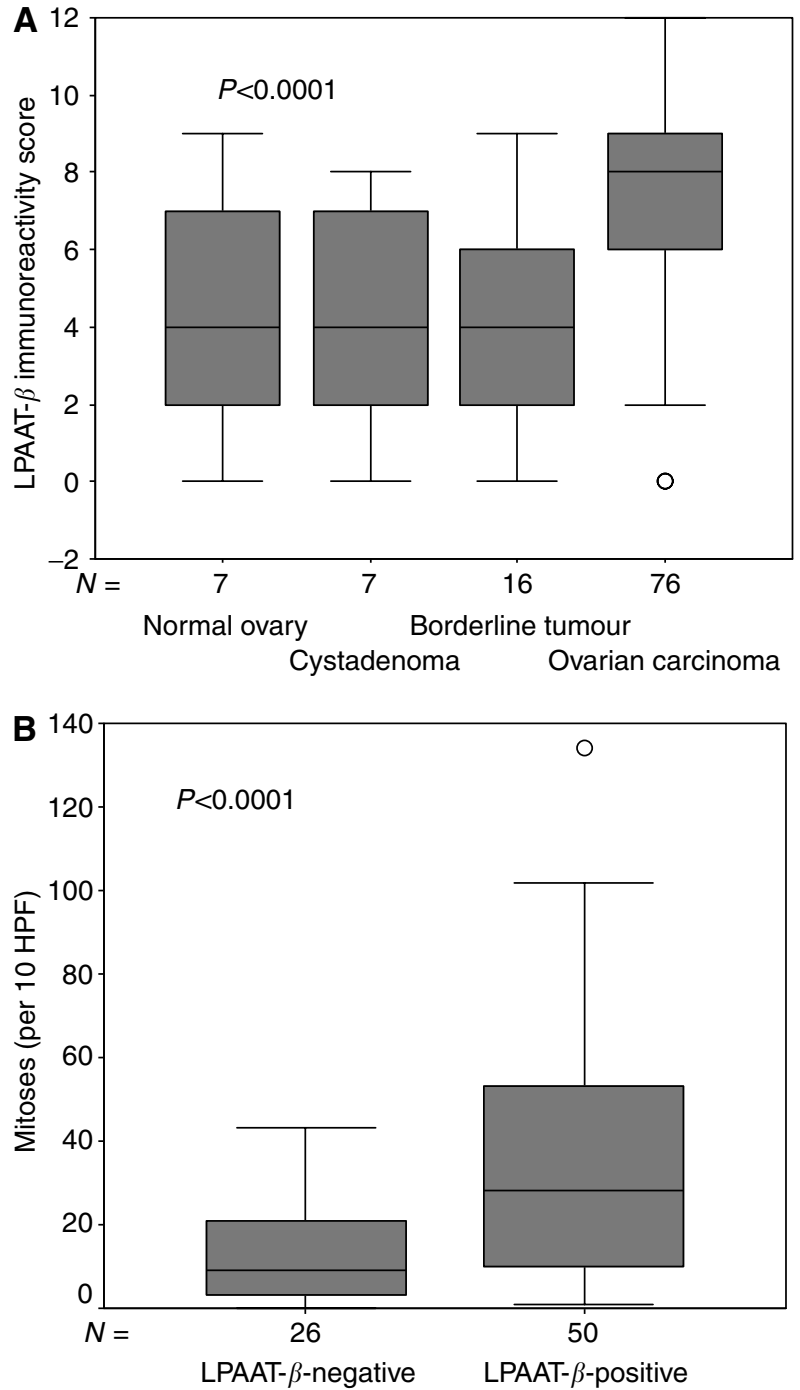

Figure 3 Median immunoreactivity score for LPAAT- $\beta$ staining in normal ovaries, cystadenomas, borderline tumours and ovarian carcinomas $(P=P$-value, Kruskal-Wallis test) $(\mathbf{A})$. Median number of mitoses (per 10 HPF $)$ in tumours positive and negative for LPAAT- $\beta(P=P$-value MannWhitney test) (B). $N=$ number of cases; HPF = high-power field. normal ovaries were LPAAT- $\beta$-positive $\left(\chi^{2}\right.$ test $P$-value $=0.001$; Table 1). Lysophosphatidic acid acyltransferase beta immunoreactivity score was significantly higher in ovarian carcinomas than in benign ovarian tissue, which comprises borderline tumours, cystadenomas and normal ovarian surface epithelium, as determined with the Kruskal-Wallis test $(P<0.0001)$. Median LPAAT- $\beta$ immunoreactivity score was 8 in the cases of ovarian carcinoma, while it was 4 in the cases with borderline tumours, cystadenomas or normal ovarian surface epithelium (Figure $3 \mathrm{~A}$ ).

In addition, in most cases (96\%), weak LPAAT- $\beta$ immunoreactivity was found in the stroma of ovarian tumours and normal ovaries where a homogenous staining pattern was observed.

\section{Association of LPAAT- $\beta$ expression with clinicopathological parameters}

Malignant tumours are characterised by clinicopathological parameters such as tumour stage and tumour grade. An association of a certain marker with these parameters could possibly point to a tumourbiological function of the protein.

We found a significant association of LPAAT- $\beta$ expression with tumour grading $(P=0.044)$ comparing low-grade cases (G1 and G2) with high-grade cases (G3) (Table 2). As the Silverberg grading system includes nuclear polymorphism, mitotic frequency and

Table 2 Association of LPAAT- $\beta$ expression and various clinicopathological factors

\begin{tabular}{|c|c|c|c|c|}
\hline Characteristic & All cases & $\begin{array}{l}\text { LPAAT- } \\
\beta \text {-negative }\end{array}$ & $\begin{array}{l}\text { LPAAT- } \\
\beta \text {-positive }\end{array}$ & $P$-value \\
\hline $\begin{array}{l}\text { Histological type } \\
\text { Differentiated }\end{array}$ & $64(100 \%)$ & $25(39 \%)$ & $39(61 \%)$ & \\
\hline Undifferentiated & $12(100 \%)$ & | (8\%) & I| (92\%) & $0.049^{a}$ \\
\hline \multicolumn{5}{|c|}{ Histological grade (Silverberg) } \\
\hline GI-2 & $49(100 \%)$ & $21(43 \%)$ & $28(57 \%)$ & \\
\hline G3 & $27(100 \%)$ & $5(19 \%)$ & $22(81 \%)$ & $0.044^{\mathrm{a}}$ \\
\hline \multicolumn{5}{|l|}{ PT } \\
\hline pTI & $15(100 \%)$ & $9(60 \%)$ & $6(40 \%)$ & \\
\hline PT2-3 & $61(100 \%)$ & $17(28 \%)$ & $44(72 \%)$ & $0.032^{\mathrm{a}}$ \\
\hline \multicolumn{5}{|l|}{ PN } \\
\hline $\mathrm{pNO}$ & $25(100 \%)$ & $9(36 \%)$ & $16(64 \%)$ & \\
\hline $\mathrm{pNI}$ & $21(100 \%)$ & 7 (33\%) & $14(67 \%)$ & $1.0^{\mathrm{a}}$ \\
\hline \multicolumn{5}{|l|}{$P M$} \\
\hline PMX & $72(100 \%)$ & $24(33 \%)$ & $48(67 \%)$ & \\
\hline pMI & $4(100 \%)$ & $2(50 \%)$ & $2(50 \%)$ & $0.6^{\mathrm{a}}$ \\
\hline \multicolumn{5}{|l|}{ FIGO stage } \\
\hline 1 & $16(100 \%)$ & $8(50 \%)$ & $8(50 \%)$ & \\
\hline$\|$ & II (100\%) & $2(18 \%)$ & $9(82 \%)$ & \\
\hline III & $45(100 \%)$ & $14(31 \%)$ & 31 (69\%) & \\
\hline IV & $4(100 \%)$ & $2(50 \%)$ & $2(50 \%)$ & $0.47^{b}$ \\
\hline \multicolumn{5}{|l|}{ Residual tumour } \\
\hline$<2 \mathrm{~cm}$ & $26(100 \%)$ & $9(35 \%)$ & $17(65 \%)$ & \\
\hline$>2 \mathrm{~cm}$ & $6(100 \%)$ & I (I7\%) & $5(83 \%)$ & $0.64^{\mathrm{a}}$ \\
\hline \multicolumn{5}{|l|}{ Chemotherapy } \\
\hline Platinum-based CTX & $44(100 \%)$ & $16(36 \%)$ & $28(64 \%)$ & \\
\hline Other CTX & $4(100 \%)$ & I (25\%) & $3(75 \%)$ & \\
\hline No CTX & $7(100 \%)$ & $4(57 \%)$ & $3(43 \%)$ & $0.4^{c}$ \\
\hline \multicolumn{5}{|l|}{ Age at surgery (years) } \\
\hline$<60$ & $45(100 \%)$ & $17(38 \%)$ & $28(62 \%)$ & \\
\hline$>60$ & $31(100 \%)$ & $9(29 \%)$ & $22(7 \mid \%)$ & $0.47^{\mathrm{a}}$ \\
\hline
\end{tabular}

${ }^{\mathrm{a}}$ Fisher's exact test, two-sided. ${ }^{\mathrm{b}} \chi^{2}$ for trends. 'Pearson's $\chi^{2}$, two-sided. 
Table 3 Univariate Kaplan-Meier survival analysis: median overall survival time of all patients with invasive ovarian carcinoma in dependence of clinicopathological factors and LPAAT- $\beta$ expression

\begin{tabular}{|c|c|c|c|c|}
\hline Characteristic & $\begin{array}{l}\text { No. of } \\
\text { cases }\end{array}$ & $\begin{array}{l}\text { Median survival } \\
\text { time (months) }\end{array}$ & $\begin{array}{c}\text { Standard } \\
\text { error }\end{array}$ & $\begin{array}{c}\text { Log-rank } \\
P \text {-value }\end{array}$ \\
\hline \multicolumn{5}{|l|}{ LPAAT- $\beta$ expression } \\
\hline Negative & 26 & Not reached & - & \\
\hline Positive & 50 & 41.5 & 8.4 & 0.17 \\
\hline \multicolumn{5}{|l|}{ Histological type } \\
\hline Differentiated & 64 & 51.4 & 6.6 & \\
\hline Undifferentiated & 12 & 17.8 & - & 0.24 \\
\hline \multicolumn{5}{|l|}{ PT } \\
\hline pTI & 15 & Not reached & - & \\
\hline pT2 & 13 & 61.6 & 21.8 & \\
\hline PT3 & 48 & 41.2 & 4.6 & 0.12 \\
\hline \multicolumn{5}{|l|}{ PN } \\
\hline $\mathrm{pNO}$ & 25 & 61.6 & - & \\
\hline $\mathrm{pNI}$ & 21 & Not reached & - & 0.4 \\
\hline \multicolumn{5}{|l|}{ FIGO stage } \\
\hline 1 & 16 & Not reached & - & \\
\hline$\|$ & || & 52.5 & 18.4 & \\
\hline III & 45 & 41.5 & 7.0 & \\
\hline IV & 4 & 1.7 & 5.3 & $<0.00001$ \\
\hline \multicolumn{5}{|l|}{$\begin{array}{l}\text { Histological grade } \\
\text { (Silverberg) }\end{array}$} \\
\hline GI & 18 & Not reached & - & \\
\hline G2 & 31 & 47.5 & 5.4 & \\
\hline G3 & 27 & 34.8 & 5.6 & 0.013 \\
\hline \multicolumn{5}{|l|}{ Age at surgery (years) } \\
\hline$<60$ & 45 & 61.6 & - & \\
\hline$>60$ & 31 & 35.5 & 15.9 & 0.044 \\
\hline
\end{tabular}

architectural features, we determined associations of LPAAT- $\beta$ immunoreactivity with these factors. Expression of LPAAT- $\beta$ showed a significant positive correlation with mitotic figure count (per $10 \mathrm{HPF}$ ), as determined by the Mann-Whitney test $(P<0.0001)$ (Figure 3B). No association of the expression of the enzyme could be observed with nuclear polymorphism or architectural features.

A significant positive association $(P=0.032)$ of LPAAT- $\beta$ expression with tumour stage could be established. Tumours of the pT 2 and pT 3 stages were more frequently positive for LPAAT- $\beta$ than tumours of the pT1 stage (Table 2). Significant associations of LPAAT- $\beta$ expression with neither nodal status nor state of distant metastasis could be observed. Also, no significant association with FIGO stage was evident.

Consistent with the association of LPAAT- $\beta$ expression and tumour grade, we found that undifferentiated carcinomas had a significantly higher LPAAT- $\beta$ immunoreactivity than carcinomas of a distinct histological type (serous, mucinous, endometrioid, transitional cell or clear cell) $(P=0.049)$ (Table 2$)$.

Stromal expression of LPAAT- $\beta$ was associated with neither epithelial expression of the protein nor with any clinicopathological parameter.

\section{Univariate survival analysis}

The known prognostic factors in ovarian carcinoma like FIGO stage, state of metastasis as well as tumour grade and age at diagnosis were prognostic factors for overall survival (Table 3)
Table 4 Univariate Kaplan-Meier survival analysis: median overall and progression-free survival time of patients with invasive ovarian carcinoma in different age groups in dependence of LPAAT- $\beta$ expression

\begin{tabular}{|c|c|c|c|c|}
\hline Characteristic & $\begin{array}{l}\text { No. of } \\
\text { cases }\end{array}$ & $\begin{array}{l}\text { Median survival } \\
\text { time (months) }\end{array}$ & $\begin{array}{l}\text { Standard } \\
\text { error }\end{array}$ & $\begin{array}{c}\text { Log-rank } \\
P \text {-value }\end{array}$ \\
\hline \\
\hline \multirow{2}{*}{\multicolumn{5}{|c|}{$\begin{array}{l}\text { Age }<60 \\
\end{array}$}} \\
\hline & & & & \multirow[b]{3}{*}{0.024} \\
\hline Negative & 17 & \multirow{2}{*}{$\begin{array}{c}\text { Not reached } \\
41.5\end{array}$} & - & \\
\hline Positve & 28 & & 6.9 & \\
\hline \multicolumn{5}{|c|}{ Age $>60$} \\
\hline \multicolumn{5}{|c|}{ LPAAT- $\beta$ expression } \\
\hline Negative & 9 & 17.9 & 1.6 & \multirow[b]{2}{*}{0.29} \\
\hline Positive & 22 & 35.5 & 15.2 & \\
\hline \multirow{3}{*}{\multicolumn{5}{|c|}{$\begin{array}{l}\text { Progression-free survival } \\
\text { Age }<60 \\
\text { LPAAT- } \beta \text { expression }\end{array}$}} \\
\hline & & & & \\
\hline & & & & \\
\hline Negative & 14 & \multirow{2}{*}{$\begin{array}{c}\text { Not reached } \\
21.3\end{array}$} & - & \multirow[b]{2}{*}{0.012} \\
\hline Positve & 18 & & 14.2 & \\
\hline \multicolumn{5}{|c|}{ Age $>60$} \\
\hline \multicolumn{5}{|c|}{ LPAAT- $\beta$ expression } \\
\hline Negative & 7 & 17.6 & 4.8 & \\
\hline Positive & 12 & 29.8 & 7.5 & 0.28 \\
\hline
\end{tabular}

as well as for progression-free survival (Table 4) in our study group.

Median overall survival was 41.5 months for patients with LPAAT- $\beta$-positive carcinomas, while it was not reached at the end of follow-up in the group of patients with LPAAT- $\beta$-negative carcinomas (Figure 4A). Nevertheless, this difference was not statistically significant $(P=0.17)$. Similarly, there was no significant difference in progression-free survival $(P=0.11)$ between both groups (not shown). However, we found that LPAAT- $\beta$ positivity was a negative prognostic parameter in patients younger than 60 years at the time of diagnosis. As shown in Figure $4 \mathrm{~B}$, the median overall survival time for patients younger than 60 years with LPAAT- $\beta$-positive tumours was 41.5 months, while it was not reached for patients of the same age group with LPAAT- $\beta$-negative tumours $(P=0.024)$. Similarly, progression-free survival was significantly shorter in patients younger than 60 years with LPAAT- $\beta$-positive tumours (21.3 months $v s$ not reached, $P=0.012$; Figure $4 \mathrm{D})$. Patients with LPAAT- $\beta$-positive tumours had similar frequences of local recurrence and distant metastasis as patients with LPAAT- $\beta$-negative tumours (not shown). No significant difference in progression-free or overall survival according to LPAAT- $\beta$ was determined for patients older than 60 years (not shown). A preliminary explorative multivariate analysis for the two age groups indicated that the number of cases was too small to obtain reliable results. Survival analysis was not biased by differences in therapy as LPAAT- $\beta$ expression was associated with neither residual tumour mass nor type of chemotherapy (Table 2).

\section{DISCUSSION}

In this study, we systematically determined the expression of LPAAT- $\beta$ mRNA as well as LPAAT- $\beta$ protein in vivo and in vitro in ovarian carcinomas and in benign ovarian tissue. We found that LPAAT- $\beta$ mRNA was expressed in all ovarian tissue samples and all ovarian cell lines examined. On the protein level, LPAAT- $\beta$ was expressed in most ovarian carcinomas $(66 \%)$ but only in a minority of benign ovarian samples. Comparative analysis finally 

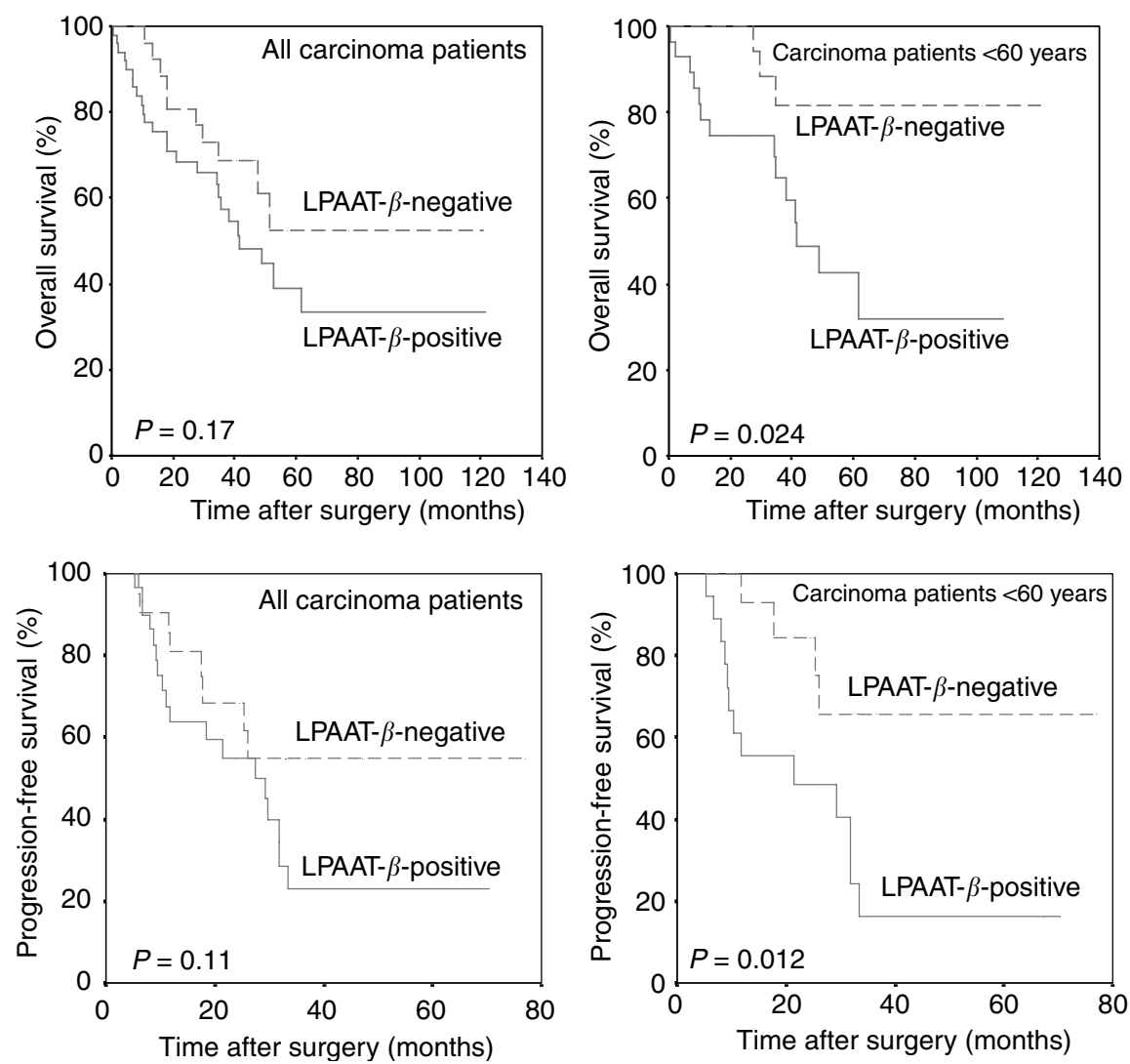

Figure 4 Univariate survival analysis (Kaplan-Meier) for all 76 patients with invasive carcinomas. There was no significant difference in median overall survival in patients with tumours negative or positive for LPAAT- $\beta(\mathbf{A})$. For patients younger than 60 years, median overall survival was significantly reduced if they had tumours positive for LPAAT- $\beta$ (B). Patients with LPAAT- $\beta$-positive tumours showed no significant difference in progression-free survival compared to patients with LPAAT- $\beta$-negative tumours $(\mathbf{C})$. Lysophosphatidic acid acyltransferase beta positivity in patients younger than 60 years was a predictor of reduced progression-free survival $(\mathbf{D}) . P=P$-value, log-rank test.

revealed a strong increase of LPAAT- $\beta$ expression in invasive ovarian carcinomas compared to normal ovarian surface epithelium, cystadenomas and borderline tumours. Consequently, our study shows an overexpression of LPAAT- $\beta$ in malignant ovarian tissue.

Our finding that LPAAT- $\beta$ expression was upregulated in invasive ovarian carcinomas is consistent with other studies, which reported LPAAT- $\beta$ upregulation in malignant tissue: LPAAT- $\beta$ mRNA expression determined by Northern blot analysis was low to moderate in normal ovarian, breast and prostate tissue while it was high in the corresponding malignant tissue (Leung, 2001). Tissue expression of the protein as determined by immunohistochemistry was elevated in malignant neoplasms of the prostate, breast, lung, colon, cervix, brain as well as ovary compared to normal tissue of the same type (Bonham et al, 2003). Furthermore, cell culture experiments showed that prostate carcinoma cell lines expressed LPAAT- $\beta$ at a higher level than normal prostate cell strains and that this correlated with an increase with LPAAT- $\beta$ activity (Bonham et al, 2001, 2003).

In our study, we found an increased LPAAT- $\beta$ expression in poorly differentiated tumours as well as an association with tumour size and high mitotic count. This indicates that LPAAT- $\beta$ expression may be involved in the regulation of tumour cell proliferation. This hypothesis, on the functional level, is supported by the results of other authors who reported that transduction and overexpression of the LPAAT- $\beta$ gene in weakly transformed cancer cells in vitro lead to the ability to proliferate in low serum (Bonham et al, 2001, 2003). These data suggest a cause and effect relationship between LPAAT- $\beta$ function and tumour progression, as opposed to just circumstantial evidence of increased expression in tumours; it appears to be a selective advantage to tumours, possibly by enhanced response to growth factors in cell signalling pathways requiring PA. Phosphatidic acid, the product of LPAAT- $\beta$, has been shown to play an important role in several signal transduction pathways that stimulate proliferation and prevent apoptosis. Thus, it is necessary for translocation of raf to membranes, a step being essential for raf activation (Andresen et al, 2002). Furthermore, PA is involved in mTOR activation (Fang et al, 2001), which in turn plays a role in the Akt/PI3K pathway in preventing apoptosis. There is evidence that PA can directly activate ERK (Andresen et al, 2002). In addition, overexpression of LPAAT- $\beta$, but not the alpha isoform, cDNA in Xenopus oocytes enhanced both raf- and ras-mediated activation of ERK and associated germinal vessel breakdown (Coon et al, 2003). Phosphatidic acid is also implicated in the activation of Rho family proteins like Rac (Chuang et al, 1993), RhoA (Lee et al, 1998) and Arf (Manifava et al, 2001). These small GTPases in regulating the actin cytoskeleton play a role in cellular migration and invasion and, in addition, promote cell cycle progression by regulation of cell cycle proteins like p21 and cyclin D1 (EtienneManneville and Hall, 2002). Further messenger functions of PA include EGFR internalisation (Shen et al, 2001), vesicle formation (English, 1996; English et al, 1996) and calcium homeostasis (English, 1996; English et al, 1996). Several of these pathways are activated in ovarian carcinoma as was shown for EGFR, PI3K or Akt (Berchuck et al, 1990; Wenham et al, 2002; Zhang et al, 2003). Enhanced PA signalling in LPAAT- $\beta$-overexpressing tumours may contribute to this deregulation and result in tumour growth and 
dedifferentiation. Phosphatidic acid-mediated activation of Rho proteins, which have been shown to be implicated in the progression in ovarian cancer (Horiuchi et al, 2003), could enhance invasion, metastasis and proliferation. The hypothesis that PA itself has an impact on ovarian carcinoma tumorigensis is supported by the fact that PA directly stimulates proliferation in ovarian cancer cell lines (Xu et al, 1995). Our finding of an increased LPAAT- $\beta$ expression in worse differentiated and more advanced tumours may reflect these biological mechanisms.

Further evidence for an important role of LPAAT- $\beta$ in human cell signalling pathways came from experiments with specific LPAAT- $\beta$ inhibitors. Treatment of smooth muscle cells, in which cell signalling pathways have been well characterised, decreased phosphorylation of ERK, Akt and mTOR (Coon et al, 2003). Moreover, LPAAT- $\beta$ inhibition of a variety of human tumour cell lines leads to a proliferation arrest in $\mathrm{G}_{2}-\mathrm{M}$ and subsequent apoptosis (Bonham et al, 2003; Coon et al, 2003; Hideshima et al, 2003). Interestingly, a proapoptotic effect of the LPAAT- $\beta$ inhibitors was found in most tumour cell lines, which also comprised ovarian cancer cell lines, but not in some normal cell types, even when high concentrations of inhibitors were used (Bonham et al, 2003; Coon et al, 2003). Lysophosphatidic acid acyltransferase beta, which normally is expressed in low levels in most normal tissues, may not be necessary for survival of these normal cells, but the malignant cells may be more dependent on its activity. Thus, a future scenario in cancer therapy might be to use LPAAT- $\beta$ inhibitors for patients with LPAAT- $\beta$-overexpressing tumours to specifically suppress multiple pathways of neoplastic cell growth.

In the present study, LPAAT- $\beta$ positivity was a predictor of unfavourable outcome with respect to overall and progression-free

\section{REFERENCES}

Aguado B, Campbell RD (1998) Characterization of a human lysophosphatidic acid acyltransferase that is encoded by a gene located in the class III region of the human major histocompatibility complex. J Biol Chem 273: $4096-4105$

Almadrones LA (2003) Treatment advances in ovarian cancer. Cancer Nurs 26: $16-20$

Andresen BT, Rizzo MA, Shome K, Romero G (2002) The role of phosphatidic acid in the regulation of the Ras/MEK/Erk signaling cascade. FEBS Lett 531: $65-68$

Berchuck A, Kamel A, Whitaker R, Kerns B, Olt G, Kinney R, Soper JT, Dodge R, Clarke-Pearson DL, Marks P (1990) Overexpression of HER-2/ neu is associated with poor survival in advanced epithelial ovarian cancer. Cancer Res 50: 4087-4091

Bonham L, Hollenback D, Leung D, White T, Morrison D, Finney RE (2001) Validation of lysophosphatidic acid acyltransferase-b (LPAAT-b) as a novel target for anti-cancer drug discovery and development. Proc Am Assoc Cancer Res 670 (Abstract \#3608)

Bonham L, Leung DW, White T, Hollenback D, Klein P, Tulinsky J, Coon M, De Vries P, Singer JW (2003) Lysophosphatidic acid acyltransferasebeta: a novel target for induction of tumour cell apoptosis. Expert Opin Ther Targets 7: 643-661

Chuang TH, Bohl BP, Bokoch GM (1993) Biologically active lipids are regulators of Rac.GDI complexation. J Biol Chem 268: 2620626211

Coon M, Ball A, Pound J, Ap S, Hollenback D, White T, Tulinsky J, Bonham L, Morrison DK, Finney R, Singer JW (2003) Inhibition of lysophosphatidic acid acyltransferase beta disrupts proliferative and survival signals in normal cells and induces apoptosis of tumor cells. Mol Cancer Ther 2: $1067-1078$

Eberhardt C, Gray PW, Tjoelker LW (1997) Human lysophosphatidic acid acyltransferase. cDNA cloning, expression, and localization to chromosome 9q34.3. J Biol Chem 272: 20299-20305

English D (1996) Phosphatidic acid: a lipid messenger involved in intracellular and extracellular signalling. Cell Signal 8: $341-347$

English D, Cui Y, Siddiqui RA (1996) Messenger functions of phosphatidic acid. Chem Phys Lipids 80: 117-132 survival in patients, younger than 60 years. This might indicate that in younger patients, hormonal influences act together with LPAAT- $\beta$ expression to worsen the prognosis. In this context, studies on the impact of oestrogen and progesterone on LPAAT- $\beta$ regulation would be of great interest. Lysophosphatidic acid acyltransferase beta expression might be of prognostic value only for certain subgroups of patients, as the expression of the enzyme was no prognostic marker for overall or progression-free survival in the whole study population. A limitation of our study was the relatively small patient number $(n=76)$, which lowers the power of a survival analysis, especially when performed for subgroups. For this reason, we could not perform a multivariate survival analysis for the different age groups.

Lysophosphatidic acid acyltransferase beta is an interesting new target for chemotherapeutical intervention in patients with ovarian carcinoma. Our study shows that LPAAT- $\beta$ is upregulated in ovarian cancer and is more prevalent in less-differentiated tumours. In addition, LPAAT- $\beta$ expression was a predictor of a worse prognosis in patients younger than 60 years. Large-scale prospective and retrospective studies are needed to establish whether LPAAT- $\beta$ expression could be of diagnostic value as a prognostic parameter for certain subgroups of patients. Furthermore, the mechanism of LPAAT- $\beta$ upregulation in tumours remains to be elucidated.

\section{ACKNOWLEDGEMENTS}

We thank Ms Ines Koch and Mr Fabian Wohlenberg for their excellent technical assistance and Dr Lynn Bonham for her comments on the manuscript.
Etienne-Manneville S, Hall A (2002) Rho GTPases in cell biology. Nature 420: $629-635$

Fang Y, Vilella-Bach M, Bachmann R, Flanigan A, Chen J (2001) Phosphatidic acid-mediated mitogenic activation of mTOR signaling. Science 294: 1942 - 1945

Hideshima T, Chauhan D, Hayashi T, Podar K, Akiyama M, Mitsiades C, MItsiades N, Gong B, Bonham L, de Vries P, Munshi N, Richardson PG, Singer JW, Anderson KC (2003) Antitumor activity of lysophosphatidic acid acyltransferase-beta inhibitors, a novel class of agents, in multiple myeloma. Cancer Res 63: 8428-8436

Horiuchi A, Imai T, Wang C, Ohira S, Feng Y, Nikaido T, Konishi I (2003) Up-regulation of small GTPases, RhoA and RhoC, is associated with tumor progression in ovarian carcinoma. Lab Invest 83: 861-870

Jemal A, Tiwari RC, Murray T, Ghafoor A, Samuels A, Ward E, Feuer EJ, Thun MJ (2004) Cancer statistics, 2004. CA Cancer J Clin 54: 8-29

Lee ZW, Kweon SM, Kim BC, Leem SH, Shin I, Kim JH, Ha KS (1998) Phosphatidic acid-induced elevation of intracellular $\mathrm{Ca}^{2+}$ is mediated by RhoA and $\mathrm{H} 2 \mathrm{O} 2$ in Rat-2 fibroblasts. J Biol Chem 273: $12710-12715$

Leung DW (2001) The structure and functions of human lysophosphatidic acid acyltransferases. Front Biosci 6: $944-953$

Li D, Yu L, Wu H, Shan Y, Guo J, Dang Y, Wei Y, Zhao S (2003) Cloning and identification of the human LPAAT-zeta gene, a novel member of the lysophosphatidic acid acyltransferase family. J Hum Genet 48: $438-442$

Manifava M, Thuring JW, Lim ZY, Packman L, Holmes AB, Ktistakis NT (2001) Differential binding of traffic-related proteins to phosphatidic acid- or phosphatidylinositol (4,5)- bisphosphate-coupled affinity reagents. J Biol Chem 276: 8987 - 8994

Mills GB, Moolenaar WH (2003) The emerging role of lysophosphatidic acid in cancer. Nat Rev Cancer 3: $582-591$

Pfisterer J, Hilpert F, Du Bois A, Meier W, Wagner U (2003) State-of-the-art first-line treatment of ovarian cancer. Onkologie 26: 446-450

Shen Y, Xu L, Foster DA (2001) Role for phospholipase D in receptormediated endocytosis. Mol Cell Biol 21: 595-602

Shimizu Y, Kamoi S, Amada S, Hasumi K, Akiyama F, Silverberg SG (1998) Toward the development of a universal grading system for ovarian epithelial carcinoma. Gynecol Oncol 70: 2-12 
Tsao SW, Mok SC, Fey EG, Fletcher JA, Wan TS, Chew EC, Muto MG, Knapp RC, Berkowitz RS (1995) Characterization of human ovarian surface epithelial cells immortalized by human papilloma viral oncogenes (HPV-E6E7 ORFs). Exp Cell Res 218: 499-507

Wenham RM, Lancaster JM, Berchuck A (2002) Molecular aspects of ovarian cancer. Best Pract Res Clin Obstet Gynaecol 16: 483-497

West J, Tompkins CK, Balantac N, Nudelman E, Meengs B, White T, Bursten S, Coleman J, Kumar A, Singer JW, Leung DW (1997) Cloning and expression of two human lysophosphatidic acid acyltransferase

cDNAs that enhance cytokine-induced signaling responses in cells. DNA Cell Biol 16: 691-701

Xu Y, Fang XJ, Casey G, Mills GB (1995) Lysophospholipids activate ovarian and breast cancer cells. Biochem J 309: $933-940$

Zhang L, Yang N, Katsaros D, Huang W, Park JW, Fracchioli S, Vezzani C, Rigault de la Longrais IA, Yao W, Rubin SC, Coukos G (2003) The oncogene phosphatidylinositol 3'-kinase catalytic subunit alpha promotes angiogenesis via vascular endothelial growth factor in ovarian carcinoma. Cancer Res 63: 4225-4231 